\title{
The contribution of male-sterility mutations to inbreeding depression in Mimulus guttatus
}

\author{
JOHN H. WILLIS* \\ Department of Biology, University of Oregon, Eugene, OR 97403, U.S.A.
}

\begin{abstract}
The magnitude of inbreeding depression can influence many aspects of a population's ecology and evolution, including the nature of selection acting on the mating system and the chances that the population will go extinct during periods of small population size. If inbreeding depression is caused primarily by recessive mutations of large effect on fitness, such as lethals or steriles, then it is expected to be purged rapidly by selection with moderate amounts of inbreeding. In contrast, inbreeding depression primarily caused by many genes with mild effects on fitness will not be rapidly purged with inbreeding, so it should be a more resilient barrier to the evolution of self-fertilization and a more significant threat to the survival of endangered species. Here I show that recessive male-sterility alleles at individual loci are common in a primarily outcrossing population of the plant Mimulus guttatus. Despite the high frequency of these major mutations, most of the inbreeding depression for male fertility and cumulative measures of lifetime fitness results from more mildly deleterious alleles. Malesterility alleles contribute to $31 \%$ of the inbreeding depression for the fraction of viable pollen grains, and to $26 \%$ of the inbreeding depression for total fitness. These results suggest that most of the inbreeding depression for male fertility in this population would not be purged, in the short term, with moderate inbreeding.
\end{abstract}

Keywords: deleterious mutations, genetic load, inbreeding depression, male sterility, Mimulus, pollen viability.

\section{Introduction}

Inbreeding depression, the decreased fitness of inbred individuals as compared to outcrossed individuals, is routinely observed in outcrossing animals and plants, and heterosis is commonly observed in self-fertilizing species (Wright, 1977; Charlesworth \& Charlesworth, 1987). It is well known that inbreeding depression can be a powerful selective force favouring the evolution of outbreeding mechanisms (Darwin, 1862, 1877) and can be important in the breeding of crops and livestock (Darwin, 1868). Avoidance of inbreeding depression is also critical to the conservation of endangered species of plants and animals (Soulé, 1986; Lynch \& Gabriel, 1990; Hedrick \& Miller, 1992). The importance of inbreeding depression to these diverse areas of ecology and evolution can depend on its genetic basis.

Inbreeding depression may be caused either by loci in which the heterozygote has higher fitness than both

*E-mail: jwillis@oregon.uoregon.edu

(C) 1999 The Genetical Society of Great Britain. homozygotes, or by recessive deleterious mutations that are maintained in populations by mutation-selection balance. Genetic studies of inbreeding depression in Drosophila (reviewed by Simmons \& Crow, 1977; Crow \& Simmons, 1983; Crow, 1993; Charlesworth \& Hughes, 1999), crop species (reviewed by Mather \& Jinks, 1982; Jinks, 1983; Sprague, 1983), ferns (Klekowski, 1970, 1976, 1984; Hedrick, 1987), and several wild flowering plant species (Barrett \& Charlesworth, 1991; Willis, 1992; Fu \& Ritland, 1994; Johnston \& Schoen, 1995; Dudash \& Carr, 1998) provide no support for the hypothesis of heterozygote advantage. In contrast, these studies and others mentioned below provide substantial support for the hypothesis that most inbreeding depression is caused by deleterious recessive mutations.

Unfortunately, we know relatively little about the extent to which mutations with large effects on fitness, like recessive lethals or steriles, rather than more mildly deleterious mutations, contribute to inbreeding depression. Most information we do have comes from studies of egg to adult viability in Drosophila. The distribution of inbred viabilities in Drosophila is strongly bimodal, 
with approximately half of the inbreeding depression for viability caused by nearly recessive lethals and the remainder by the segregation of many partially recessive genes of small effect (reviewed by Lewontin, 1974; Simmons \& Crow, 1977; Crow \& Simmons, 1983; Charlesworth \& Charlesworth, 1987; Ashburner, 1989). Male- and female-sterility mutations contribute to inbreeding depression for fertility in fruit flies (i.e. Ashburner, 1989). Mutations of large effect on fitness, such as recessive lethals or male-sterility mutations, also contribute to inbreeding depression in plants (Crumpacker, 1967; Klekowski, 1970, 1984, 1988b; Ohnishi, 1982; Hedrick, 1987; Kaul, 1988; Willis, 1992).

A knowledge of the relative contribution of mutations of large effect to inbreeding depression is critical to several problems in evolution, conservation biology and agriculture. This is because if inbreeding depression in an outcrossed population is primarily caused by recessive lethal or sterile mutations, then it is expected to be rapidly purged with even a small amount to inbreeding (Lande \& Schemske, 1985; Charlesworth et al., 1990; Uyenoyama \& Waller, 1991). Alternatively, the purging with inbreeding is much less effective if inbreeding depression is caused by many, partially recessive mutations of small effect on fitness (Lande \& Schemske, 1985; Charlesworth et al., 1990). For this reason, inbreeding depression resulting from mildly deleterious mutations may: (i) be a more resilient barrier to the evolution of selfing than inbreeding depression of the same magnitude resulting from recessive lethal or sterility mutations; (ii) hinder the production by plant and animal breeders of inbred agricultural varieties that are as productive as $F_{1}$ hybrids (Mather \& Jinks, 1982; Falconer, 1989); and (iii) increase the chances of extinction when a formerly abundant, outbred species is exposed to the inbreeding effects of small population size (Barrett \& Charlesworth, 1991; Hedrick, 1994).

The primary reason that we know so little about the relative contribution of mutations of large effect to inbreeding depression is that for most traits in most organisms it is exceedingly difficult to ascertain whether an individual has low fitness because of homozygosity at a single locus, environmental effects, or the cumulative effects of deleterious alleles at multiple loci. For example, it is usually impossible to conduct inheritance studies on seeds that do not germinate or on plants that fail to flower. One trait with which it is possible to study directly the contribution of major mutations to inbreeding depression is male fertility in plants. Many plants are hermaphroditic, and male-sterile mutations usually do not cause female sterility (Kaul, 1988; Chaudhury, 1993). Any male-sterile plants that are discovered in an inbreeding depression experiment can then be used in crossing studies as female parents, so that it can be determined whether the sterility is caused by homozygosity at a single nuclear locus.

The purpose of this study is to determine the relative contribution of mutations of large effect to inbreeding depression for male fertility in a large, mainly outcrossing population of the wild flower Mimulus guttatus. Previous studies have shown that there is severe inbreeding depression for a component of male fertility, pollen viability, in this population, and that some inbred plants seem to be completely male-sterile (Willis, 1993a). Inbreeding depression for pollen viability has also been detected in other populations of Mimulus (Ritland \& Ganders, 1987b; Carr \& Dudash, 1996, 1997). The experiments outlined below are designed to determine: (i) the frequency of male sterility among inbred plants and its relative contribution to inbreeding depression for components of male fertility and measures of fitness throughout the life cycle; and (ii) whether complete male sterility is caused by homozygosity at single loci or by the cumulative effects of many mildly deleterious alleles.

\section{Materials and methods}

\section{Study species and population}

The common yellow monkey flower, Mimulus guttatus (Scrophulariaceae), is abundant throughout western North America. This species usually inhabits moist areas and can be found along stream banks, roadsides, on cliff faces, and in wet meadows from Alaska to Mexico, and as far east as the Rockies (Pennell, 1951). Depending on the seasonal availability of moisture, plants may exist either as annuals or rhizomed perennials. Mimulus guttatus is self-compatible with perfect, hermaphroditic flowers, and populations vary tremendously in terms of the degree of self-fertilization (Ritland \& Ganders, 1987a; Ritland, 1990; Dudash \& Ritland, 1991; Dole \& Ritland, 1993; Willis, 1993b). For the past several years I have been studying the ecological genetics of a very large, annual population of $M$. guttatus. The population is situated on open seep on Iron Mountain in Oregon's Western Cascades, and consists of hundreds of thousands of plants. Outcrossing rates measured over two years vary from about 0.75 to 1.0 , and there is substantial inbreeding depression in the field and greenhouse for most components of fitness and morphological and phenological traits (Willis, 1992, 1993a,b, 1996).

\section{Relative contribution of male sterility to Inbreeding depression}

A simple procedure was used for determining the relative contribution of male sterility to inbreeding 
depression. First, I measured inbreeding depression caused by both severe and mildly deleterious mutations by comparing the average fitnesses of outcrossed and selfed plants in a large experiment. Secondly, malesterile individuals were identified and saved for studies of inheritance. Finally, inbreeding depression resulting from mildly deleterious alleles, without the contribution of major mutations, was estimated by excluding malesterile individuals from the data and then re-estimating inbreeding depression.

At the start of this study, I collected 530 maternal seed families from the wild Iron Mountain Population. These seeds had unknown histories of inbreeding. Seeds from each maternal family were germinated in the University of Oregon greenhouse, and one seedling from each family was randomly selected, grown to maturity, and randomly outcrossed to produce 1200 different full-sib seed families. Seed from 900 of these families was germinated in the greenhouse, and one seedling per family was randomly selected to serve as parents in this experiment. Three hundred plants were randomly chosen to produce self-fertilized progeny, whereas the other 600 plants were randomly paired to produce 300 independent outcrossed full-sib families. All outcrossed and selfed pollinations were performed on flowers that had been emasculated in the bud stage by pulling off the emerging corolla, which in Mimulus is attached to the anthers. Because some plants died prior to flowering, and some crosses failed, the final sample size was 277 outcrossed families and 295 selfed families.

About 20 seeds per family were counted and sown in 2.25 inch pots filled with soil-less Sunshine potting mix, with one pot per family. Because of low seed numbers in some families, the average number of seeds planted per family was 17.5. Pots were placed in a completely randomized order on a single greenhouse bench under 230 watt sodium lights ( $16 \mathrm{~h}$ day, $8 \mathrm{~h}$ night), and were watered regularly without fertilizer to ensure that the soil mix remained moist. Pots were censused for seedlings 18 days after seeds were sown, when germination had essentially ceased. Germination success was scored as the ratio of seedlings to seeds sown. One seedling per family was randomly selected to be measured for later components of fitness, and the other seedlings were discarded. This crossing design, with complete independence of all plants within and between crossing treatments, is especially powerful for the measurement of inbreeding depression at the population level (Lynch, 1988).

Male fertility per flower was estimated by counting viable and inviable pollen grains from the first flower produced on each plant. On the day that the flower opened, all four anthers were removed from the corolla, placed in Eppendorf tubes with $60 \mu \mathrm{L}$ of aniline blue in lactophenol (Radford et al., 1974; Kearns \& Inouye, 1993), and lightly crushed with glass rods to release the pollen. A total volume of $1.6 \mu \mathrm{L}$ from each Eppendorf tube was scored in haemocytometers for the number of viable and inviable pollen grains. Pollen grains were scored as viable if they stained a dark blue. From these counts I obtained three nonindependent measures of male fertility per flower: the number of viable pollen grains per flower, the fraction of total pollen grains that were viable, and the total number of pollen grains per flower.

Female fertility per flower was estimated by the average number of seeds produced by the first two flowers, which had been hand-pollinated with excess fertile pollen. A highly fertile inbred line $(F>0.96)$ was used as the pollen source for these crosses, in order to ensure that variation in pollen quality did not contribute to variation in seed counts. Because seed production was not limited by pollen in this experiment, seed counts should be approximately equal to the number of viable ovules per flower. I refer throughout to these seed counts as 'ovules per flower' for this reason, and also to avoid potential confusion with the more typically reported trait 'seeds per flower', which can refer to seed counts obtained from any number of different pollination treatments.

Eight weeks after the seeds were sown, every plant was scored for the total number of flowers produced. Flower number could then be combined with male and female fertility per flower, and germination success, to provide measures of lifetime fitness in the greenhouse through both male and female function.

In total there were six fitness components measured in this study: the proportion of seeds that germinated, the number of flowers produced per seedling, the number of viable pollen grains per flower, the fraction of pollen grains that were viable, the total number of pollen grains per flower, and the number of ovules per flower. Cumulative measures of fitness through either male or female function were also obtained for each family by multiplying the fraction of seed germinated in each family by the total number of pollen grains (number of flowers $\times$ viable pollen grains per flower) or ovules (number of flowers $\times$ number of ovules per flower) produced by that family's seedling. To obtain a measure of total lifetime fitness through male and female function, I first divided each plant's total number of viable pollen grains and total number of ovules by the mean total pollen and total ovules of outcrossed plants. Standardizing total male and female gamete production in this way equalizes mean outcrossed gamete production through male and female function. This standardization of gamete production implies that on average each outcrossed plant successfully reproduces itself. This 
seems reasonable, because the Iron Mountain population is roughly constant in population size from year to year, and is primarily outcrossing. In order to compute, for each family, a measure of cumulative fitness through lifetime gamete production, I simply summed each plant's standardized male and female gamete production and then multiplied this total gamete production by the fraction of seeds that germinated in that family.

I conducted $t$-tests in order to test whether selfed progeny had different mean phenotypes from outcrossed progeny. These tests were conducted for each component of fitness, as well as for the three measures of cumulative fitness. Inbreeding depression was measured as $\delta=1 \quad \bar{w}_{\mathrm{s}}$, where $\bar{w}_{\mathrm{s}}$ is the mean fitness component of selfed progeny and $\bar{w}_{\mathrm{O}}$ is the mean fitness of outcrossed progeny. Approximate standard errors of inbreeding depression were obtained by using the delta method for calculating the variance, $V$, of a ratio (Lynch $\&$ Walsh, 1998):

$V\left(\frac{\bar{w}_{\mathrm{s}}}{\bar{w}_{\mathrm{o}}}\right) \approx\left(\frac{\bar{w}_{\mathrm{s}}}{\bar{w}_{\mathrm{o}}}\right)^{2}\left(\frac{V\left(\bar{w}_{\mathrm{s}}\right)}{\bar{w}_{\mathrm{s}}^{2}}+\frac{V\left(\bar{w}_{\mathrm{o}}\right)}{\bar{w}_{\mathrm{o}}^{2}}\right)$.

Because the selfed and outcrossed plants were completely independent samples in this study, the usual covariance term in this formula is absent.

\section{Inheritance of male sterility}

The first step in the genetic analysis of male sterility is to determine whether the complete sterility of individuals is caused by single genes of large effect, or by the cumulative effects of several genes of minor effect. The simplest hypothesis for the genetic basis of sterility is that it is caused by homozygosity of a recessive allele at a single nuclear locus, and there are numerous examples of such mutations in diverse species of flowering plants (Kaul, 1988; Chaudhury, 1993). To test this hypothesis in $M$. guttatus, I pollinated male-sterile individuals, randomly selected from the plants isolated above, with pollen from fully fertile inbred lines and then backcrossed a single $F_{1}$ per family to their sterile parent. If male sterility resulted from a single nuclear locus, then one would expect $50 \%$ of these backcross progeny to be male-sterile.

Plants were defined as being functionally male-sterile if they had values of the components of male fertility (number of viable pollen per flower or fraction of viable pollen grains) that were less than $10 \%$ of the mean of outcrossed plants (see Results for justification). An arbitrary sample of 11 selfed plants that were identified as male-sterile based on the fraction of viable pollen grains was retained and crossed. More male- sterile plants were not retained for analysis because of limitations on greenhouse space and time, rather than low viability of the male-sterile plants. $F_{1}$ seeds from these crosses were germinated in the greenhouse, and one flowering $F_{1}$ in each family was backcrossed to its sterile parent. All $F_{1}$ plants had high pollen viability and pollen production typical of outcrossed plants (data not presented), suggesting that male sterility is recessive.

Approximately 50-60 seeds per backcross family were planted individually in 2.25 inch pots containing Sunshine soil-less mix. Because of low seed germination success in some families, only nine families produced a reasonable number $(>20)$ of flowering progeny to be included in the results presented below. As in the inbreeding depression experiment, pots were placed in a randomized order beneath sodium lights in the greenhouse. Pollen from the first several flowers produced on each plant was collected and placed on microscope slides to which one drop of aniline blue was added. The slides were examined under a compound microscope and 100 pollen grains per plant were scored as viable or inviable. Plants were classified as male-sterile if they had less than $10 \%$ of the outcrossed mean pollen viability in the inbreeding depression experiment ( $7 \%$ viable pollen; see Results). Tests for deviations from Mendelian inheritance were conducted using $\chi^{2}$-tests with one degree of freedom.

\section{Results}

\section{Inbreeding depression for fitness components and measures of cumulative fitness}

Table 1 shows the mean values of fitness components and cumulative measures of fitness for selfed and outcrossed progeny. Selfed progeny exhibited significantly lower values for every fitness component measured, except for proportion of seeds germinated (Table 1). For example, selfed progeny produced $13 \%$ fewer flowers, $30 \%$ fewer viable pollen grains per flower, and $16 \%$ fewer ovules per flower than outcrossed progeny. Selfed progeny also exhibited significantly lower measures of cumulative fitness through male function, female function, and combined male and female fertilities (Table 1). The reduction in the fitness of selfed progeny relative to outcrossed progeny ranged from $30 \%$ to $42 \%$ for these composite measures of fitness.

Figure 1 shows the frequency distributions of two components of male fertility, the fraction of viable pollen grains and the number of viable pollen grains per flower, for outcrossed and selfed plants. The fraction of viable pollen grains per flower shows a strong bimodal 
Table 1 Fitness components and cumulative fitness traits in outcrossed and selfed Mimulus guttatus

\begin{tabular}{|c|c|c|c|c|c|}
\hline Trait & Cross & $N$ & Mean & SE & $t$-value \\
\hline Proportion germination & $\begin{array}{l}\text { Outcrossed } \\
\text { Selfed }\end{array}$ & $\begin{array}{l}277 \\
295\end{array}$ & $\begin{array}{l}0.60 \\
0.57\end{array}$ & $\begin{array}{l}0.02 \\
0.02\end{array}$ & 1.05 \\
\hline Number of flowers & $\begin{array}{l}\text { Outcrossed } \\
\text { Selfed }\end{array}$ & $\begin{array}{l}267 \\
283\end{array}$ & $\begin{array}{l}20.93 \\
18.22\end{array}$ & $\begin{array}{l}0.77 \\
0.69\end{array}$ & $2.63 * *$ \\
\hline Viable pollen per flower & $\begin{array}{l}\text { Outcrossed } \\
\text { Selfed }\end{array}$ & $\begin{array}{l}250 \\
265\end{array}$ & $\begin{array}{l}237.21 \\
166.28\end{array}$ & $\begin{array}{r}11.64 \\
8.03\end{array}$ & $5.07^{* * *}$ \\
\hline Fraction of viable pollen & $\begin{array}{l}\text { Outcrossed } \\
\text { Selfed }\end{array}$ & $\begin{array}{l}250 \\
265\end{array}$ & $\begin{array}{l}0.69 \\
0.56\end{array}$ & $\begin{array}{l}0.01 \\
0.01\end{array}$ & $7.11^{* * * *}$ \\
\hline Pollen grains per flower & $\begin{array}{l}\text { Outcrossed } \\
\text { Selfed }\end{array}$ & $\begin{array}{l}250 \\
265\end{array}$ & $\begin{array}{l}322.16 \\
270.48\end{array}$ & $\begin{array}{r}13.15 \\
9.41\end{array}$ & $3.22 * *$ \\
\hline Ovules per flower & $\begin{array}{l}\text { Outcrossed } \\
\text { Selfed }\end{array}$ & $\begin{array}{l}248 \\
257\end{array}$ & $\begin{array}{l}124.34 \\
104.82\end{array}$ & $\begin{array}{l}5.05 \\
4.42\end{array}$ & $2.92 * *$ \\
\hline Germination to viable pollen & $\begin{array}{l}\text { Outcrossed } \\
\text { Selfed }\end{array}$ & $\begin{array}{l}277 \\
295\end{array}$ & $\begin{array}{l}3024.57 \\
1746.38\end{array}$ & $\begin{array}{l}231.43 \\
127.27\end{array}$ & $4.92 * * *$ \\
\hline Germination to ovules & $\begin{array}{l}\text { Outcrossed } \\
\text { Selfed }\end{array}$ & $\begin{array}{l}277 \\
295\end{array}$ & $\begin{array}{l}1464.81 \\
1033.33\end{array}$ & $\begin{array}{l}95.38 \\
72.80\end{array}$ & $3.62 * * *$ \\
\hline Germination to total gametes & $\begin{array}{l}\text { Outcrossed } \\
\text { Selfed }\end{array}$ & $\begin{array}{l}277 \\
290\end{array}$ & $\begin{array}{l}1.22 \\
0.78\end{array}$ & $\begin{array}{l}0.08 \\
0.05\end{array}$ & $4.94 * * *$ \\
\hline
\end{tabular}

$* * P<0.01, * * * P<0.001$.

distribution of male fertilities in selfed plants, in contrast to the roughly unimodal distributions for outcrossed plants. The distribution for viable pollen per flower in selfed plants is not as obviously bimodal. For both traits, inbreeding dramatically increases the proportion of plants that are nearly or completely male-sterile. There were numerous selfed plants that failed to produce any pollen grains, or produced greater than about $95 \%$ inviable pollen grains. Some of the malesterile plants had shrivelled or green anthers that lacked pollen, whereas others produced white, inviable pollen in large amounts. These plants are essentially malesterile. Examination of the distributions of male fertility (Fig. 1) suggests that it is reasonable to define a plant as being functionally male-sterile if it has a measure for the fraction of viable pollen that is less than about $10 \%$ of the outcrossed mean. According to this definition, 17 of 265 selfed plants were male-sterile.

Table 2 presents the average values of male fitness components and cumulative measures of fitness for selfed plants, excluding those that were male-sterile $(<10 \%$ of the outcrossed mean for pollen viability, as described above). Because 17 plants with low fitness values were excluded, these mean values for the fraction of viable pollen, cumulative fitness from germination to total viable pollen production, and cumulative fitness from germination to total male and female gamete production are somewhat greater than the mean values of selfed plants presented in Table 1. There was no difference in mean flower number between male-sterile $(20.8 \pm 2.7)$ and fertile inbred plants $(19.2 \pm 0.7)$, so the interpretation of the results for cumulative fitness measures is not complicated by possible negative effects of sterility on autogamous seed and/or fruit set, which can result in increased flower production in M. guttatus (Macnair \& Cumbes, 1990).

One can estimate the inbreeding depression for these three measures of fitness from the complete data set (Table 1) and for the data set excluding the selfed sterile plants (Table 2). Figure 2 shows the inbreeding depression and its standard error for these traits for the complete data set and for the data set with selfed sterile plants excluded. The estimates of inbreeding depression for all three traits were less when steriles were excluded from the analyses than those for the whole data set. Although statistical comparison of the inbreeding depression values with and without steriles is not strictly valid because one data set is a subset of the other, the standard errors suggest that this reduction in inbreeding depression is not statistically significant (Fig. 2). One can estimate the relative amount of inbreeding depression that is caused by recessive sterility mutations by calculating one minus the ratio of inbreeding depression without steriles to inbreeding depression based on all the data. Using this method, 
(a)

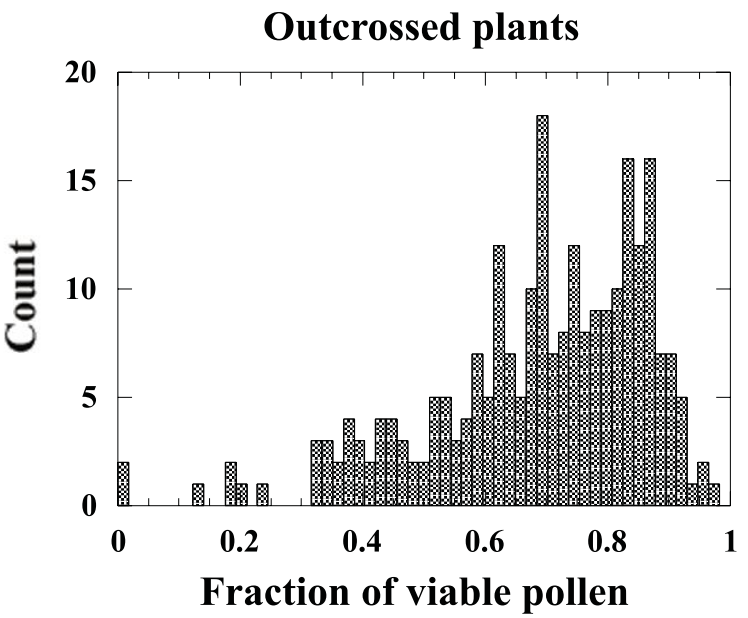

(c)

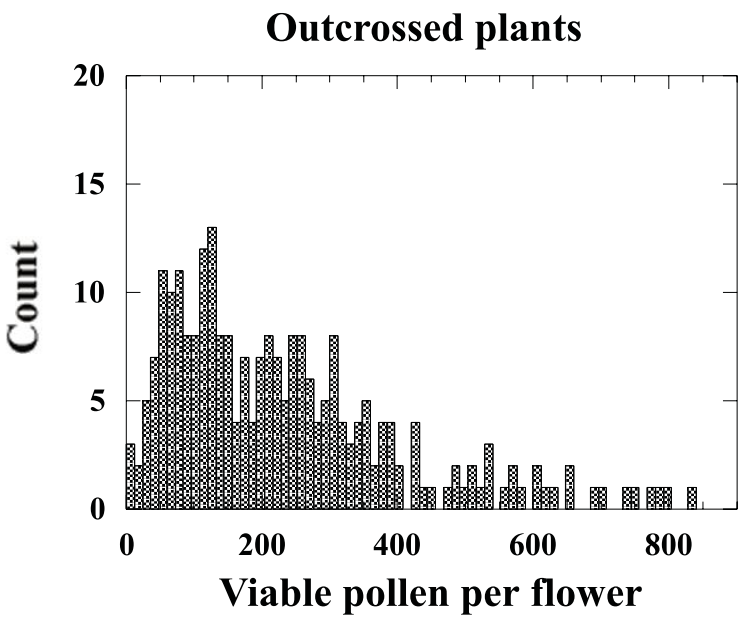

(b)

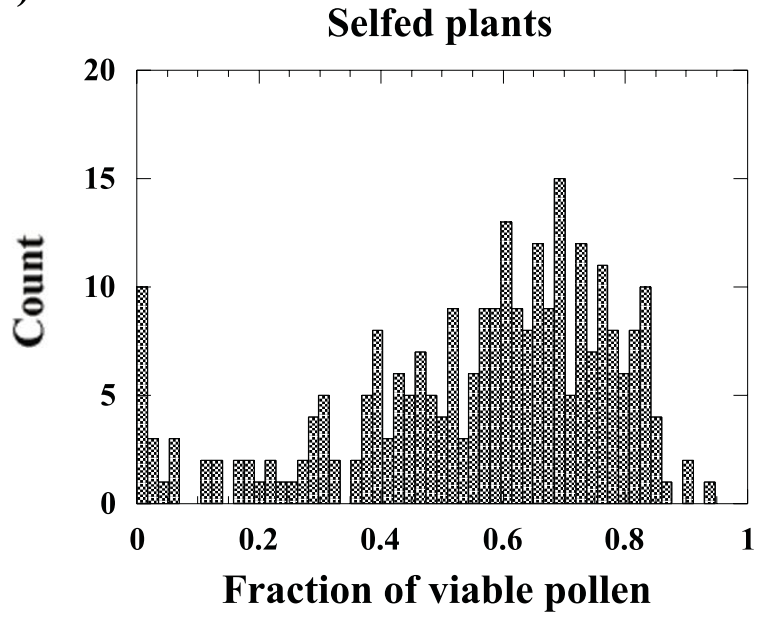

(d)

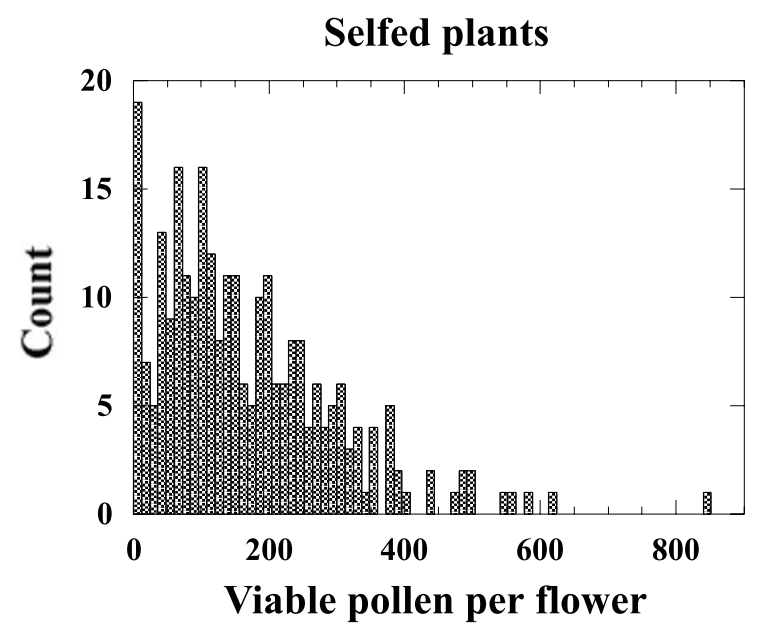

Fig. 1 Histograms of two components of male fertility in Mimulus guttatus, the fraction of pollen grains that are viable and the number of viable pollen grains produced per flower, for outcrossed and selfed progeny.

Table 2 Fraction of viable pollen and cumulative fitness traits of selfed Mimulus guttatus, excluding plants that are male-sterile

\begin{tabular}{lrrr}
\hline Trait & $N$ & Selfed mean & \multicolumn{1}{c}{ SE } \\
\hline Fraction of viable pollen & 248 & 0.60 & 0.01 \\
Germination to viable pollen & 247 & 2082.36 & 142.47 \\
Germination to total gametes & 247 & 0.90 & 0.05 \\
\hline
\end{tabular}

Individuals were scored as sterile if fraction viable pollen $\leq 0.07$.

I estimate that about $31 \%$ of the inbreeding depression for the fraction of viable pollen grains and $26 \%$ of the inbreeding depression based on cumulative fitness through male function and total gamete production is caused by recessive sterility mutations.

\section{Inheritance of male sterility}

Table 3 shows the segregation of male sterility in nine backcross families. Eight of the families had ratios of sterile offspring that were consistent with the $1: 1$ ratios expected under the hypothesis that male sterility is caused by homozygosity of a recessive allele at a single locus. In contrast, fertile progeny were much less frequent than expected in family 583, where only three of 38 progeny were fertile $(P<0.001$; Table 3$)$. If one pools the data from all families except family 583, then the resulting frequencies of sterile and fertile progeny are not significantly different from that expected with singlelocus inheritance of male sterility. These results suggest that most of the male-sterile plants identified in the inbreeding depression experiment described above were homozygous single-locus recessive sterility mutations. 


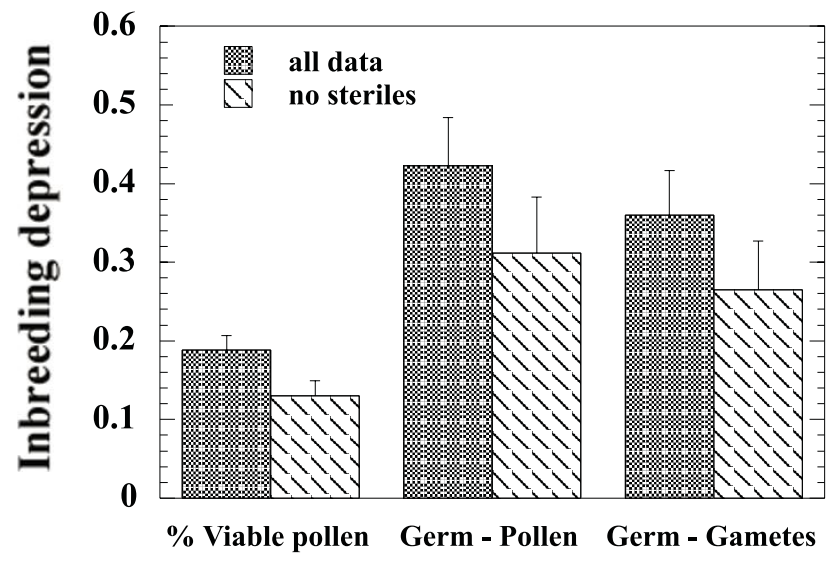

Fig. 2 The magnitudes of inbreeding depression estimated in Mimulus guttatus from all the data from outcrossed and selfed progeny, and from a subset of the data with selfed male-sterile plants excluded. Presented are the values of inbreeding depression, and one standard error, for the fraction of viable pollen grains, cumulative fitness from germination to total number of viable pollen grains produced, and cumulative fitness from germination to total male and female gamete production. Plants are classified as male-sterile if their fraction of viable pollen grains is $\leq 0.07$ (see Results).

\section{Discussion}

In this study I have shown that there is substantial inbreeding depression for components of male fertility, as well as for cumulative measures of fitness that include life history stages from seed germination to total gamete production through male and female function. The number of viable pollen grains produced per flower (male fertility) exhibited greater inbreeding depression than any other measured component of fitness. Part of

Table 3 Segregation of male sterility in backcross families of Mimulus guttatus

\begin{tabular}{lccc}
\hline Family ID & $\begin{array}{c}\text { Number of } \\
\text { fertile progeny }\end{array}$ & $\begin{array}{c}\text { Number of } \\
\text { sterile progeny }\end{array}$ & $\chi_{1}^{2}$ \\
\hline 332 & 8 & 13 & 1.19 \\
333 & 25 & 17 & 1.52 \\
399 & 26 & 22 & 0.33 \\
464 & 17 & 11 & 1.29 \\
504 & 23 & 25 & 0.08 \\
583 & 3 & 35 & $26.95^{* * *}$ \\
597 & 18 & 27 & 1.80 \\
1119 & 19 & 22 & 0.22 \\
1187 & 20 & 31 & 1.96 \\
Total, & 156 & 168 & 0.44 \\
excluding 583 & & & \\
\hline
\end{tabular}

$* * * P<0.001$. the inbreeding load for male fertility was caused by functional male sterility. I have demonstrated that for most of such plants, male sterility is inherited as a simple single-locus recessive factor. Despite the high frequency of male-steriles among the inbred progeny, they account for only $31 \%$ of the inbreeding depression for the fraction of viable pollen grains, and for only $26 \%$ of the inbreeding depression for lifetime male and female gamete production. Most of the inbreeding depression for male fertility is caused by more mildly deleterious genes.

Complete or nearly complete male sterility was common among the inbred plants from this population. When male sterility is defined in terms of the fraction of viable pollen grains produced per flower, then among the selfed progeny about $6.4 \%$ were male-steriles. The studies of inheritance of male sterility show that eight of nine steriles have segregation ratios of sterility among their backcross progeny that are consistent with singlelocus inheritance of a recessive trait (Table 3). The exception is family 583 , which shows significantly fewer fertile backcross progeny than one would expect under the hypothesis of single-locus recessive inheritance. Although crossing experiments are in progress, at this point it is not clear how male sterility is inherited in this family. Possible simple explanations include multiple independently acting nuclear sterility factors, such that homozygosity at any one of them would cause sterility, or cytoplasmic sterility. Neither hypothesis seems likely, because in the former case one would have to posit an inordinately large number of male-sterility mutations in a single individual, and in the latter case one would have to explain how the $F_{1}$ was male-fertile. Other possibilities which are being investigated include interactions between cytoplasmic and nuclear factors. Regardless, it is clear that most of the sterility observed in this population is inherited in a simple Mendelian fashion.

Given that most of the male sterility is caused by single-locus recessive alleles, one can estimate the frequency of heterozygous carriers of male sterility in this population. Because a single plant per family was scored for male fertility in this study, and the chances of obtaining a male-sterile in a single selfed offspring from a carrier are $1 / 4$, the frequency of carriers of male sterility in the outcrossed segment of this population must be $\approx 0.26$. The inference that about one quarter of the outcrossed plants in this population carry recessive male-sterility factors indicates that many different loci must be involved. Also, selection against male sterility is only half as severe in outcrossing, hermaphroditic plants as it is in selfing or dioecious species, because malesterile plants can still contribute genes to the next generation through the female function. The large number of nuclear male-sterility mutations in this

(C) The Genetical Society of Great Britain, Heredity, 83, 337-346. 
population of $M$. guttatus clearly provides ample genetic variation for the evolution of gynodioecy. That such dimorphic mating systems are unknown in this genus suggests that selection, rather than a lack of genetic variability, is maintaining hermaphroditism.

Although male-sterility mutations are abundant in this population, they are responsible for only about $31 \%$ of the inbreeding depression for pollen viability, and for about $26 \%$ of that for lifetime fitness. Although the role of lethal and sterility mutations in causing inbreeding load has been well studied in Drosophila, this is the first study on a natural population of plants which quantifies the relative contribution of a class of major deleterious mutations to inbreeding depression. Other studies have shown that lethals contribute to inbreeding depression in plant populations, but their importance relative to more mildly deleterious mutations has not been quantified. For example, studies of natural fern populations have shown that gametophytic and sporophytic lethals can be abundant (Klekowski, 1970, 1976, 1984; Ganders, 1972; Hedrick, 1987). Lethal chlorophyll-deficient mutations also can be common in plant populations (Crumpacker, 1967; Wettstein et al., 1971; Ohnishi, 1982; Klekowski, 1988a; Willis, 1992). In this and another population, chlorophyll-deficient lethals seem to contribute only slightly to inbreeding depression, although their contribution was not quantified (Willis, 1993b). Indirect evidence from a survey of inbreeding depression studies suggests that major mutations contribute to inbreeding depression for early stages of zygote development and seed germination in outcrossing plant species, whereas inbreeding depression at later stages of the life cycle is caused primarily by mildly deleterious mutations (Husband \& Schemske, 1996). Unfortunately, most of the studies on inbreeding depression reviewed by Husband \& Schemske (1996) did not examine components of male fertility, so that the extent to which male-sterility mutations contribute to inbreeding depression in other taxa is not clear.

If it turns out that much of the inbreeding load in outcrossing species is caused by mildly deleterious mutations, and not by recessive lethals or steriles, then inbreeding depression may not easily be purged from populations during short-term periods of inbreeding. Lande \& Schemske (1985), in discussing a model of inbreeding depression arising from major deleterious mutations, argued that moderate inbreeding caused by periodic bottlenecks or pollination failures could reduce inbreeding depression in an historically outcrossed plant population to a level where it no longer could selectively maintain outcrossing. The results presented here suggest that the evolution of self-fertilization is less likely to occur following brief periods of inbreeding than suggested by Lande \& Schemske (1985), because little short-term purging of inbreeding depression caused by mildly deleterious alleles will be expected to occur.

The harmful effects of inbreeding are generally appreciated by conservation biologists, who usually seek to maintain genetic variability while reducing the impact of inbreeding depression in endangered or threatened species (e.g. Hedrick \& Miller, 1992). In contrast, Templeton $\& \operatorname{Read}(1983,1984)$ argued that intentional inbreeding of historically outcrossed endangered species could rapidly reduce or eliminate inbreeding depression caused by deleterious mutations, thereby increasing the chances that the species could persist over the long-term. More recently others have made similar recommendations (e.g. Fenster $\&$ Dudash, 1994). The main problem with this idea is that if inbreeding depression is mainly caused by many mildly deleterious mutations, as suggested by this study, then such drastic inbreeding will fail to purge inbreeding depression, and will probably cause the species to go extinct (Hedrick, 1994).

One limitation of the study presented here is that the contribution of only one class of major mutations to inbreeding depression was investigated. It is possible that major deleterious mutations affecting other stages of the life history could make a greater contribution to inbreeding depression. Ideally one would like to know what the total impact of all classes of major mutations is on inbreeding depression throughout the life cycle of a species. We are currently conducting such a study on the same population of $M$. guttatus studied here by comparing inbreeding depression in the whole population to that in an experimental population from which major mutations at all stages of the life cycle have been selectively purged.

\section{Acknowledgements}

I thank B. Philip, S. Durand, S. Belcher, A. Decker, L. Biado, S. Patapoff, A. Cherbas and additional Biology students for their tireless and skilful assistance in conducting these experiments. I thank J. Kelly for his insightful comments on the manuscript. This work was supported in part by grants from the National Science Foundation, grants DEB-9419884 and DEB-9727578.

\section{References}

ASHBurner, M. 1989. Drosophila. A Laboratory Handbook. Cold Spring Harbor Laboratory Press, Cold Spring Harbor, NY. BARRETT, S. C. H. AND CHARLESWORTH, D. 1991. Effect of a change in the level of inbreeding on the genetic load. Nature, 352, 522-524.

CARR, D. E. AND DUDASH, M. R. 1996. Inbreeding depression in two species of Mimulus (Scrophulariaceae) with contrasting mating systems. Am. J. Bot., 83, 586-593. 
CARR, D. E. AND DUDASH, M. R. 1997. The effects of five generations of enforced selfing on potential male and female function in Mimulus guttatus. Evolution, 51, 1797-1807.

CHARLESWORTH, B. AND HUGHES, K. A. 1999. The maintenance of genetic variation in life-history traits. In: Singh, R. S. and Krimbas, C. B. (eds) Evolutionary Genetics from Molecules to Morphology, pp. 369-391. Cambridge University Press, Cambridge.

CHARLESWORTH, D. AND CHARLESWORTH, B. 1987. Inbreeding depression and its evolutionary consequences. Ann. Rev. Ecol. Syst., 18, 237-268.

CHARLESWORTH, D., MORGAN, M. T. AND CHARLESWORTH, B. 1990. Inbreeding depression, genetic load and the evolution of outcrossing rates in a multi-locus system with no linkage. Evolution, 44, 1469-1489.

CHAUdHuRY, A. M. 1993. Nuclear genes controlling male fertility. Pl. Cell, 5, 1277-1283.

CRow, J. F. 1993. Mutation, mean fitness, and genetic load. Oxford Surveys in Evolutionary Biology, 9, 3-42.

CROW, J. F. AND SIMMONS, M. J. 1983. The mutation load in Drosophila. In: Ashburner, M., Carson, H. L. and Thomson, J. N., Jr (eds) The Genetics and Biology of Drosophila, pp. 1-35. Academic Press, London.

CRUMPACKER, D. w. 1967. Genetic loads in maize (Zea mays L.) and other cross-fertilized plants and animals. Evol. Biol., 1, 306- 423 .

DARWIN, C. R. 1862. The Various Contrivances by Which Orchids Are Fertilised by Insects. John Murray, London.

DARWIN, C. R. 1868. Variation of Animals and Plants Under Domestication. John Murray, London.

DARwIN, C. R. 1877. The Different Forms of Flowers on Plants of the Same Species. John Murray, London.

DOLE, J. A. AND RITLAND, K. 1993. Inbreeding depression in two Mimulus taxa measured by multigenerational changes in the inbreeding coefficient. Evolution, 47, 361-373.

DUDASH, M. R. AND CARR, D. E. 1998. Genetics underlying inbreeding depression in Mimulus with contrasting mating systems. Nature, 393, 682-684.

DUDASH, M. R. AND RITLAND, K. 1991. Multiple paternity and self-fertilization in relation to floral age in Mimulus guttatus (Scrophulariaceae). Am. J. Bot., 78, 1746-1753.

FALCONER, D. S. 1989. Introduction to Quantitative Genetics, 3rd edn. Longman, London.

FENSTER, C. B. AND DUDASH, M. R. 1994. Genetic considerations for plant population restoration and conservation. In: Bowles, M. L. and Whelan, C. J. (eds) Restoration of Endangered Species, pp. 34-62. Cambridge University Press, Cambridge.

FU, Y.-B. AND RITLAND, K. 1994. Evidence for the partial dominance of viability genes contributing to inbreeding depression in Mimulus guttatus. Genetics, 136, 323-331.

GANDERS, F. R. 1972. Heterozygosity for recessive lethals in homosporous fern populations: Thelypteris palustris and Onoclea sensibilis. Bot. J. Linn. Soc., 65, 211-221.

HEDRICK, P. W. 1987. Genetic load and the mating system in homosporous ferns. Evolution, 41, 1282-1289.

HEDRICK, P. W. 1994. Purging inbreeding depression and the probability of extinction: full-sib mating. Heredity, 73, 363-372.
HEDRICK, P. W. AND MILLER, P. S. 1992. Conservation genetics: techniques and fundamentals. Ecol. Appl., 2, 30-46.

HUSBAND, B. C. AND SCHEMSKE, D. W. 1996. Evolution of the magnitude and timing of inbreeding depression in plants. Evolution, 50, 54-70.

JINKS, J. L. 1983. Biometrical genetics of heterosis. In: Frankel, R. (ed.) Heterosis: Reappraisal of Theory and Practice, pp. 1-46. Springer, Berlin.

JOHNSTON, M. O. AND SCHOEN, D. J. 1995. Mutation rates and dominance levels of genes affecting total fitness in two angiosperm species. Science, 267, 226-229.

KAUl, M. L. H. 1988. Male Sterility in Higher Plants. Springer, Berlin.

KEARNS, C. A. AND INOUYE, D. w. 1993. Techniques for Pollination Biologists. University Press of Colorado, Niwot, CO.

KLEKOWSKI, E. J. 1970. Populational and genetic studies of a homosporous fern, Osmunda regalis. Am. J. Bot., 57, 1122-1138.

KLEKOWSKI, E. J. 1976. Genetics of recessive lethality in the fern, Osmunda regalis. J. Hered., 67, 146-148.

KLEKOWSKI, E. J. 1984. Mutational load in clonal plants: a study of two fern species. Evolution, 38, 417-426.

KLEKOWSKI, E. J. 1988a. Genetic load and its causes in longlived plants. Trees, 55, 195-203.

KLEKOWSKI, E. J. 1988b. Mutation, Developmental Selection, and Plant Evolution. Columbia University Press, New York.

LANDE, R. AND SCHEMSKE, D. W. 1985. The evolution of selffertilization and inbreeding depression in plants. I. Genetic models. Evolution, 39, 24-40.

LEWONTIN, R. C. 1974. The Genetic Basis of Evolutionary Change. Columbia University Press, New York.

LYNCH, M. 1988. Design and analysis of experiments on random genetic drift and inbreeding depression. Genetics, 120, 791-807.

LYNCH, M. AND GABRIEL, W. 1990. Mutation load and the survival of small populations. Evolution, 44, 1725-1737.

LYNCH, M. AND WALSH, B. 1998. Genetics and Analysis of Quantitative Traits. Sinauer Associates, Sunderland, MA.

MACNAIR, M. R. AND CUMBES, Q. J. 1990. The pattern of sexual resource allocation in the yellow monkey flower, Mimulus guttatus. Proc. R. Soc. B, 242, 101-107.

MATHER, K. AND JINKS, J. L. 1982. Biometrical Genetics, 3rd edn. Chapman \& Hall, London.

OHNISHI, O. 1982. Population genetics of cultivated buckwheat, Fagopyrum esculentum Moench. I. Frequency of chlorophyll-deficient mutants in Japanese populations. Jap. J. Genet., 57, 623-639.

PENNELL, F. W. 1951. Mimulus. In: Abrams, L. (ed.) Illustrated Flora of the Pacific States, pp. 688-731. Stanford University Press, Palo Alto, CA.

RADFORD, A. E., DICKSON, W. C., MASSEY, J. R. AND BELL, C. R. 1974. Vascular Plant Systematics. Harper and Row, New York.

RITLAND, K. 1990. Inferences about inbreeding depression based upon changes of the inbreeding coefficient. Evolution, 44, 1230-1241.

RITLAND, K. AND GANDERS, F. R. 1987a. Covariation of selfing rates with parental gene fixation indices within populations of Mimulus guttatus. Evolution, 41, 760-771. 
RITLAND, K. AND GANDERS, F. R. 1987b. Crossability of Mimulus guttatus in relation to components of gene fixation. Evolution, 41, 772-786.

SIMMONS, M. J. AND CROW, J.F. 1977. Mutations affecting fitness in Drosophila populations. Ann. Rev. Genet., 11, 49-78.

soulé, M. 1986. Conservation Biology. Sinauer Associates, Sunderland, MA.

SPRAGUE, G. F. 1983. Heterosis in maize: theory and practice. In: Frankel, R. (ed.) Heterosis: Reappraisal of Theory and Practice, pp. 48-70. Springer, Berlin.

TEMPLETON, A. R. AND READ, B. 1983. The elimination of inbreeding depression in a captive herd of Speke's gazelle. In: Schonewald-Cox, C. M., Chambers, S. M., Macbryde, B. and Thomas, L. (eds) Genetics and Conservation, pp. 241262. Benjamin/Cummings, Menlo Park, CA.

TEMPLETON, A. R. AND READ, B. 1984. Factors eliminating inbreeding depression in a captive herd of Speke's gazelle (Gazella spekei). Zool. Biol., 3, 177-199.

UYeNOYAMA, M. K. AND WALleR, D. M. 1991. Coevolution of self-fertilization and inbreeding depression. III. Homozygous lethal mutations at multiple loci. Theor. Pop. Biol., 40, $173-210$.
WETTSTEIN, D. V., HENNINGSEN, K. W., BOYNTON, J. E., KANNAGARA, G. C. AND NIELSEN, O. F. 1971. The genic control of chloroplast development in barley. In: Boardman, N. K. and Smillie, R. M. (eds) Autonomy and Biogenesis of Mitochondria and Chloroplasts, pp. 205-223. North Holland Press, The Hague, Netherlands.

WILLIS, J. H. 1992. Genetic analysis of inbreeding depression caused by chlorophyll-deficient lethals in Mimulus guttatus. Heredity, 69, 562-572.

WILLIS, J. H. 1993a. Effects of different levels of inbreeding on fitness components in Mimulus guttatus. Evolution, 47, 864876.

WILlIS, J. H. 1993b. Partial self-fertilization and inbreeding depression in two populations of Mimulus guttatus. Heredity, 71, 145-154.

WILLIS, J. H. 1996. Measures of phenotypic selection are biased by partial inbreeding. Evolution, 50, 1501-1511.

WRIGHT, S. 1977. Evolution and the Genetics of Populations, vol. 3, Experimental Results and Evolutionary Deductions. University of Chicago Press, Chicago. 